Review

\title{
An Emerging Role for Long Non-Coding RNA Dysregulation in Neurological Disorders
}

\author{
Chiara Fenoglio *, Elisa Ridolfi, Daniela Galimberti and Elio Scarpini \\ Department of Pathophysiology and Transplantation, University of Milan, "Dino Ferrari" Center, \\ IRCCS Cà Granda Foundation Ospedale Maggiore Policlinico, Via F.Sforza 35, Milan 20122, Italy; \\ E-Mails: elisa.ridolfi@unimi.it (E.R.); daniela.galimberti@unimi.it (D.G.); \\ elio.scarpini@unimi.it (E.S.)
}

* Author to whom correspondence should be addressed; E-Mail: chiara.fenoglio@unimi.it; Tel.: +39-02-55033858; Fax: +39-02-50320430.

Received: 14 June 2013; in revised form: 18 September 2013 / Accepted: 25 September 2013 / Published: 14 October 2013

\begin{abstract}
A novel class of transcripts, long non coding RNAs (lncRNAs), has recently emerged as key players in several biological processes, including dosage compensation, genomic imprinting, chromatin regulation, embryonic development and segmentation, stem cell pluripotency, cell fate determination and potentially many other biological processes, which still are to be elucidated. LncRNAs are pervasively transcribed in the genome and several lines of evidence correlate dysregulation of different lncRNAs to human diseases including neurological disorders. Although their mechanisms of action are yet to be fully elucidated, evidence suggests lncRNA contributions to the pathogenesis of a number of diseases. In this review, the current state of knowledge linking lncRNAs to different neurological disorders is discussed and potential future directions are considered.
\end{abstract}

Keywords: IncRNA; RNA; neurodegenerative diseases; epigenetics

\section{Introduction}

For the last few decades of the 20th century, the underlying dogma of molecular biology has been that the purpose of RNA is to direct the assembly of proteins from amino acids. A few exceptions to this paradigm were known (such as ribosomal RNA and transfer RNA, which are functional RNA macromolecules that do not code for protein). Non-coding RNAs (ncRNAs) include the familial 
"housekeeping" RNAs and the thousands of regulatory RNAs that are the subject of recent intense investigation. NcRNAs come in many different sizes and for this reason have been divided into small and long classes: small ncRNAs (sncRNA) being less than 200 nucleotides (nt), and long ncRNAs (lncRNA) greater than $200 \mathrm{nt}$ to over $100 \mathrm{~kb}$ in length [1]. The current cut-off is arbitrary and corresponds to certain biochemical fractionation protocols and excludes most categories of small infrastructural or regulatory RNAs (tRNAs, snRNAs, miRNAs, siRNAs, piRNAs, tiRNAs, spliRNAs, sdRNAs and others, Figure 1).

Figure 1. Non-coding RNAs (ncRNAs) are arbitrarily grouped basing on size. Small ncRNAs being less than 200 nucleotides and long ncRNAs greater than 200 nucleotides.

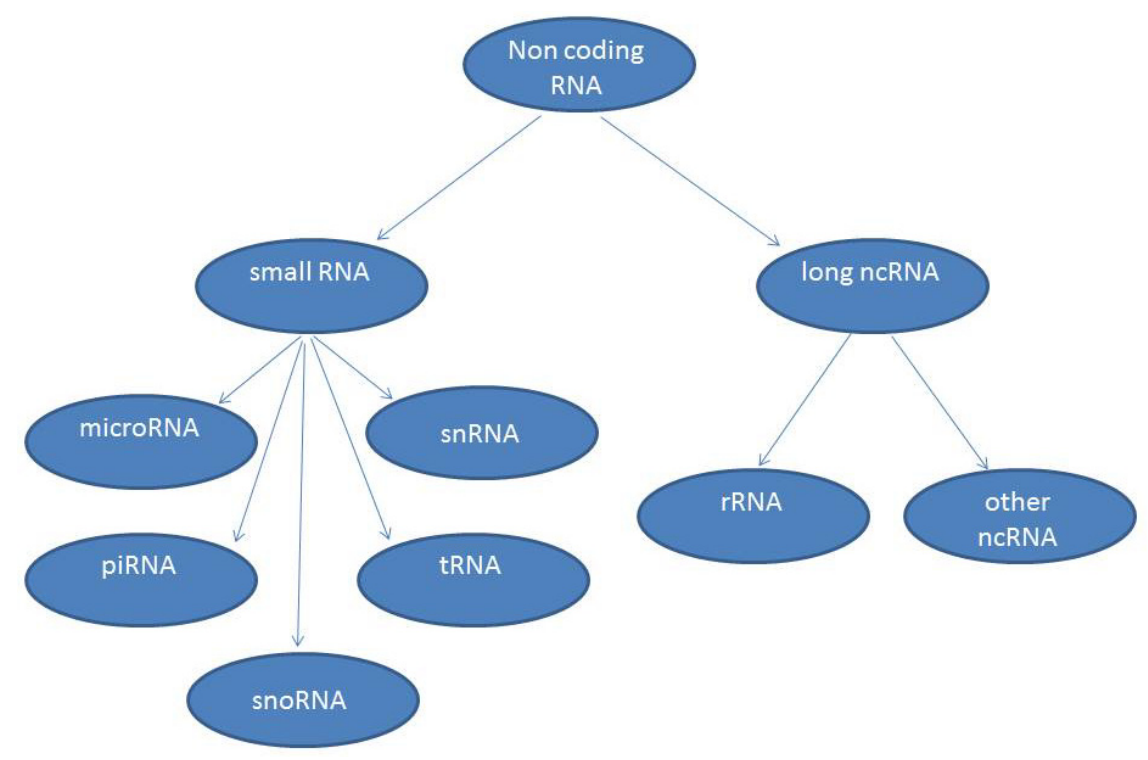

An estimation of the number of lncRNA loci from transcriptional surveys in mammals suggests that they are at least as numerous as protein-coding genes [2] with many of lncRNAs identified in intergenic regions alone [3]. With a few exceptions, it is only within the past few years that the functions and mechanisms of lncRNAs have begun to emerge.

The lncRNAs that have been studied in detail were found to be involved in different biological processes including X chromosome inactivation, nuclear structure, genomic imprinting and development.

In the following paragraphs some of the known functions of lncRNAs will be discussed with particular regard to their role in neurological disorders.

\section{Identification of IncRNAs}

Data derived from massive cloning and traditional sequencing methods have demonstrated that mammalian genomes produce thousands of RNA transcripts in addition to protein-coding genes [2]. These studies modified our simplistic view of the genome and suggested the presence of thousands of previously unknown transcripts. Recently more than 3000 intergenic ncRNAs have been found in the mammalian genome, by using information from chromatin modifications [3,4]. Evidence gained from ChIP-Seq analyses demonstrated that transcribed protein-coding genes have unusual chromatin modifications; these modifications are trimethylation of histone $\mathrm{H} 3$ at lysine $4(\mathrm{H} 3 \mathrm{~K} 4 \mathrm{me} 3)$ at the 
promoter region and trimethylation of histone $\mathrm{H} 3$ at lysine $36(\mathrm{H} 3 \mathrm{~K} 36 \mathrm{me} 3)$ in the body of the gene [5]. By eliminating these chromatin domains that correspond to protein-coding genes more than 3000 intergenic domains transcribed into lncRNAs have been found. Bioinformatics analyses showed that the majority of these transcripts have no protein-coding capability. Moreover, it was shown that many of these lncRNAs are able to interact with multiple chromatin-modifying complexes in different human and mouse cell types suggesting that lncRNAs may be involved in epigenetic regulation [3].

Recent advances in RNA sequencing technology (RNA-Seq) addressed further interrogation of the total cellular RNA, or, transcriptome, at a much higher resolution [6]. Thousands of transcripts, in addition to protein-coding mRNAs and microRNAs, have been found to be expressed in a wide range of tissues and cell types [7].

\section{Epigenetics}

Many of the lncRNAs seem to be involved in epigenetic mechanisms of gene regulation. Although the field of epigenetics earned its name over 50 years ago, just in this past decade the significance of epigenetics has been recognized in human health and disease [8]. The term epigenetics refers to changes in gene expression and/or phenotype that can be heritable without a change in the underlying DNA sequence. Several factors contribute to epigenetic mechanisms of gene regulation including DNA methylation, histone modifications, and ncRNAs. DNA methylation in the promoter region of genes is typically associated with transcriptional repression. Several mammalian enzymes are responsible for establishing and maintaining DNA methylation in the genome [9].

The modification of histone proteins has also been found in epigenetic regulation [10]. Histones are highly conserved proteins that package DNA in the nucleus and modulate the accessibility of transcription factors and RNA polymerases to DNA. Histone modifications typically take place at amino acids located in the $N$-termini of histones such as lysine, arginine and serine residues that can be acetylated or methylated (lysine and arginine) and phosphorylated (serine). Histone modifications are placed on and removed from histone residues by numerous enzymes that usually work as part of multi-protein complexes [10].

A relevant question in biology is how chromatin-modifying complexes are targeted to specific genomic loci since many of these enzymes lack DNA binding capacity. Recent studies suggest a potential role for ncRNA in driving chromatin-modifying complexes to genomic loci [11-13], however, the exact mechanism by which ncRNAs drive complexes is not known and is currently under investigation.

\section{Functions of IncRNAs}

Basing on our current knowledge of lncRNAs, it appears that such molecules are involved in many different aspects of cellular functions (reviewed in [14,15]). The roles of lncRNAs in the regulation of gene expression and organismal development are different and just beginning to be discovered. Biological processes dependent upon lncRNAs include imprinting and gene dosage regulation, stem cell pluripotency, embryonic development and segmentation, hematopoiesis, and neural cell fate determination (see for review ref [16]). LncRNAs may employ a number of mechanisms to impact gene expression via cis and trans processes. 


\subsection{Gene Imprinting}

While the function of parental gene imprinting is still unclear, lncRNAs have been found to participate in imprinting processes. These are referred to as the events that influence the monoallelic expression of a gene according to its parents of origin. Imprinting control regions (ICRs) are DNA regions that are differentially methylated depending on their parental origins. Unmethylated ICRs cause specific expression of nearby lncRNAs, which then suppress neighboring genes in cis. Several imprinted clusters contain protein-coding genes and lncRNAs that are reciprocally expressed, such as IGf2r/Air [17], Dlk1/Gtl2 [18,19], and Nesp/Nespas/Gnas [20]. Some of these lncRNAs can exert their function by recruiting epigenetic factors, such as PRC2 and G9a, in order to control the imprinted expression of neighboring coding genes [21,22].

Airn and Kcnq1ot1 are examples of lncRNAs that cause suppression of paternally inherited genes. Kcnq1ot1, in particular, is involved in the repression of several protein-coding genes in cis through interaction with repressive chromatin modifying complexes [23,24].

H19 was one of the first mammalian lncRNAs to be identified and is highly expressed in the embryo [25,26]. Though it does not seem to act as an lncRNA [27], H19 likely functions as an miRNA precursor $[28,29]$ and is mutually imprinted with the protein-coding gene $\operatorname{Ig} f 2$.

\subsection{Gene Dosage and X Chromosome Inactivation}

The $\mathrm{X}$ chromosome inactivation (XCI) indicates the mechanisms by which the difference in $\mathrm{X}$-linked gene dosage between XX females and XY males is exerted in therian mammals in which one of the two $\mathrm{X}$ chromosomes in females is silenced (the inactive $\mathrm{X}$ or $\mathrm{Xi}$ ) so that only one $\mathrm{X}$ remains active and is expressed in each female cell (the active X, or Xa) [30]. It is well-known that XCI in placental mammals is largely controlled by a cluster of lncRNA loci known as the X-inactivation center $(X i c)$ [31]. The $\mathrm{X}$ (inactive)-specific transcript (Xist) is highly expressed from Xi during the onset of $X C I$ but not from $X a$, contributing a defining moment for the realization that lncRNAs can have profound roles in the control of gene expression even though the exact mechanism of action is still not completely understood. Some evidence suggests that Xist mediates the chromosome $\mathrm{X}$ silencing effects by interacting with repressive chromatin-modifying complexes such as PRC2 [22].

Xist itself is also regulated by other lncRNAs. Initially, Xist and Tsix, its antisense transcript, transcribed from a promoter downstream of Xist, are expressed on both $\mathrm{X}$ chromosomes. However, Tsix expression continues on the $\mathrm{X}$ that will remain active $(X a)$ and this activity recruits dnmt3a to suppress Xist from being transcribed on $X a$ [32]. Conversely on $X i$, it is Tsix that is suppressed, potentially through another lncRNA that is part of the $\mathrm{X}$ inactivation center, Jpx [33]. With Tsix suppressed, the protein PRC2 is recruited to induce histone modification marks at the 5 ' end of Xist. This upregulates Xist expression on $X i$ and causes further propagation of these silencing marks throughout $\mathrm{Xi}$, which are maintained across the lifetime of the organism [33].

\subsection{Embryonic Development and Segmentation}

LncRNAs are likely implicated in processes involving animal development. The Hox genes encode homeodomain TFs that are crucial for anterior-posterior pattern formation in bilateral metazoans [34]. 
Hox genes are structured in linear clusters along the chromosome, and mammals have four paralogous clusters, Hox A, -B, -C, and -D. Several lncRNAs are encoded within these clusters, including HOTAIR (Hox antisense intergenic RNA) from HoxC, and HOTTIP and Mistral from HoxA [35-37]. The expression of Hox genes is also regulated by lncRNAs [36]. Some Hox-related lncRNAs operate in cis, having either enhancing or repressive effects. However, some like the human HOTAIR works in trans, and it is expressed from the Hox locus marking a boundary of active and inactive chromatin [35]. Furthermore, HOTAIR, similar to Xist, interacts with chromatin-modifying complexes such as PRC2 and the corepressor complex CoREST [35] and may guide these complexes to genomic loci. Overexpression of HOTAIR caused cells to become metastatic when injected into mice compared to control cells with an empty vector. Moreover, HOTAIR may serve as a scaffold for targeting chromatin-modifying complexes to chromatin [35].

Recently HOTAIR was found to be crucial for cell growth and viability and that its knockdown induced apoptosis in breast cancer cells Moreover it was found that HOTAIR is transcriptionally induced by estradiol [38]. It is possible that other lncRNAs that interact with chromatin-modifying complexes also function in a manner similar to HOTAIR.

\subsection{Stem Cell Pluripotency and Cell Fate Determination}

The promoters of more than 100 lncRNAs are bound by stem cell factors. Disruption of these lncRNAs can alter cell differentiation. The human lncRNA-RoR (RoR) is a recently identified lncRNA that is capable of reprogramming differentiated cells to induce pluripotent stem cells $[39,40]$. RoR is highly expressed both in embryonic stem cells and in induced pluripotent stem cells, due to the regulation of RoR by pluripotency transcription factors such as Oct4, Sox 2 and Nanog. Interestingly it was observed that knockdown of RoR leads to a modest increase in apoptosis and activation of p53 pathways [40]. Although the underlying mechanisms still remain to be fully clarified, Zhang et al. recently [41] demonstrated that human RoR is a strong negative regulator of p53 influencing the inhibition of p53-mediated cell cycle arrest and apoptosis.

Recently, a refined analysis from Guttman et al. [39] performed loss-of-function studies on 226 lncRNAs expressed in mouse embryonic stem cells characterizing the effects on gene expression. The authors identified 26 lncRNAs able to maintain the pluripotent status. In particular, knockdown of these lncRNAs resulted in a loss of pluripotency markers, and reduction of Nanog promoter activity. Simultaneously, expression patterns similar to differentiation into specific lineages were produced, suggesting that IncRNAs repressed differentiation programs in mouse embryonic stem cells. Altogether these findings support the hypothesis that some lncRNAs are integral members of a regulatory network, together with key pluripotent transcription factors, which modulate pluripotency and lineage-specific differentiation pathways in mouse embryonic stem cells.

lncRNAs are implicated in cell fate determination events in multiple cells lineages, including the nervous system. Taurine upregulated gene 1 (TUG1) is an lncRNA expressed in the developing retina and brain, as well as in adult tissues. It has been found that in the newborn retina, loss of TUG1 resulted in malformed or non-existent outer segments of transfected photoreceptors, thus suggesting that TUG1 is required for the proper formation of photoreceptors in the developing rodent retina [42]. Evf2 is instead a mouse lncRNA that appears to recruit Dlx and Mecp2 transcription factors to 
important DNA regulatory elements in the Dlx5-Dlx6 intergenic regions and controlled Dlx5, Dlx6 and Gad1 expression through cis and trans acting mechanisms. Evf2 mouse mutants appeared to have reduced numbers of GABAergic interneurons in early postnatal hippocampus and the dentate gyrus. This situation is restored to normality in Evf2 mutant adult hippocampus although reduced synaptic inhibition still occurred $[43,44]$.

Although many lncRNAs have been shown to regulate gene expression only a few have been shown to have other cellular functions. For example, NEAT1 has been shown to play an important role in paraspeckle formation [45]. Also NRON has a role in nuclear import/export [46]. All together, these studies suggest that the lncRNAs have different cellular functions, many of which are yet to be identified and characterized for the mechanism of their function.

\section{LncRNAs in Human Diseases}

As the functions and mechanisms of lncRNAs are beginning to emerge, there is an intense interest in identifying any potential role of these molecules in human diseases. Several studies have shown that lncRNAs are dysregulated in human pathologies, however it has yet to be shown that these molecules are enough to drive the disease status.

lncRNAs have been strongly associated with cancer [47]. Recently, the lncRNA PCAT-1, was found to promote cell proliferation and is a target of PRC2 regulation, [48]. Moreover, ANRIL, which is upregulated in prostate cancer, is required for the expression of the tumor suppressors $\mathrm{INK} 4 \mathrm{a} / \mathrm{p} 16$ and INK4b/p15 [49]. HOTAIR upregulation is associated with poor prognosis in breast cancer [11], liver [50], colorectal [51], gastrointestinal [52] and pancreatic [53] cancers and probably contributes to increase also tumor invasiveness and metastasis [11].

MALAT-1, which is another lncRNA associated with various cancers and metastasis [54] was found to affect the transcriptional and post-transcriptional regulation of cytoskeletal and extracellular matrix genes [55]. Although lncRNAs have been extensively investigated in cancers several lines of evidence suggest a possible role also in different disease conditions such as cardiovascular diseases. For example, two lncRNAs have been found to be dysregulated in heart disease; the expression of the lncRNA MIAT is associated with increased risk of myocardial infarction, whereas the lncRNA ANRIL is associated with increased risk to coronary heart disease [56,57]. Recently, a novel lncRNA has been discovered, named DBE-T, that functions in cis and localizes to the Facioscapulohumeral muscular dystrophy (FSHD) locus. FSHD is the third most common myopathy and is predominantly caused by a contraction of specific repeats mapping on chromosome 4q35 [58]. It is suggested that DBE-T likely acts as a locus control element by promoting active chromatin domains and thus FSHD would be caused from lncRNA "promoter mutations" able to perturb DBE-T regulation [58]. Furthermore, a novel lncRNA seems to be involved in the pathogenic mechanisms underneath the HELLP syndrome (hemolysis, elevated liver enzymes, low platelets) that is a recessively inherited life-threatening pregnancy complication [59].

\section{Role of IncRNAs in the Central Nervous System}

Recent evidence demonstrate that lncRNAs contribute to the complex biological system organization and gene regulatory networks of the central nervous system (CNS), affecting brain 
patterning, neural stem cell maintenance, neurogenesis and gliogenesis, stress responses, and synaptic and neural plasticity.

Mercer and colleagues identified 849 lncRNAs (among the 1328 examined), that are expressed in the adult mouse brain and found that the majority were associated with specific neuroanatomical regions, cell types, or subcellular compartments [60]. A complementary study showed that over 200 of these lncRNAs are expressed in developing and adult mouse brain and are largely derived from genomic loci located proximal to protein-coding genes with similar expression profiles in the brain [61].

Guttman et al. discovered more than 1000 evolutionarily conserved intergenic lncRNAs in mouse by analyzing chromatin signatures from four mouse cell types [5]. A functional analysis of the expression of these lncRNAs revealed the presence of a "brain cluster" of lncRNAs that is associated with biological processes including hippocampal development, oligodendrocyte (OL) myelination, brain aging, CREB and PGC1-alpha transcriptional regulation, and GABAergic neuronal (GABAN), $\mathrm{G}$ protein coupled receptor and calcineurin signaling pathways. An additional study demonstrated that 169 lncRNAs are differentially expressed during the sequential processes of mouse ventral forebrain-derived neural precursor cells mediated lineage restriction, GABAN and OL lineage specification, progressive OL lineage maturation, and terminal differentiation including myelination [62].

Detailed analyses of specific lncRNAs, dynamically expressed in the CNS, reveal potential roles in mediating neural cell fate decisions. The Sox2OT lncRNA, which contains the Sox 2 gene within one of its introns and is subsequently transcribed in the same direction [63], is expressed in regions of constitutive adult neurogenesis [60]. Moreover, Sox2OT is dynamically regulated in CNS structures during development, where it may be responsible for modulating Sox2 expression [64]. The lncRNA $\mathrm{Nkx} 2.2 \mathrm{AS}$ regulates $\mathrm{Nkx} 2.2$, a transcription factor that is critical for OL lineage specification. A recent study reported that forced expression of $\mathrm{Nkx} 2.2 \mathrm{AS}$ in NSCs in vitro enhances their differentiation along the OL lineage, in part, by inducing an increase in Nkx2.2 mRNA levels [65].

LncRNAs also modulate synaptic plasticity and promote long-term changes in synaptic strength. The rodent-specific $B C 1$ and primate-specific BC200 lncRNAs, are selectively targeted to postsynaptic dendritic compartments, where they regulate local protein synthesis by repressing the initiation of translation through an eIF4A-dependent mechanism [66-69]. Similarly, NTAB is a lncRNA that is expressed in developing and adult rat brain, where it is also found in neuronal processes [70]. Another lncRNA, MALAT-1, is enriched in hippocampal neurons, where it regulates several serine/arginine splicing factors important for synapse formation, density and maturation [71].

\subsection{Dysregulation of lncRNAs in Neurological Disorders}

\subsubsection{LncRNAs Play a Role in the Pathophysiology of Several Neurological Disorders}

Angelman syndrome (AS) is a neurodevelopmental disorder associated with genomic imprinting and characterized by severe neurologic abnormalities [72]. Ube3a-as is a lncRNA transcribed antisense to the maternally expressed Ube3a gene, mutated or deleted in AS, suggesting that Ube3a-as may repress paternal Ube3a expression. Other studies have shown that repression of Ube3a is dependent on Ube3a-as $[73,74]$. However, other data has demonstrated that silencing of paternal Ube3a can occur in 
the absence of Ube3a-as and implies a more complex regulatory relationship underlying the imprinting of Ube3a [75].

LncRNAs may influence the pathogenesis of fragile X syndrome (FXS), which is characterized by a triplet nucleotide repeat expansion in the 5'UTR of FMRl, the gene encoding the neuronal development protein, FMRP. The lncRNAs ASFMR1 and FMR4 are generated from the FMR1 gene locus. ASFMR1 has multiple alternative splicing patterns and overlaps the 5 ' untranslated region (UTR) CGG repeat region of FMR1 [76]; FMR4 is initiated upstream of the FMR1 start site. Alternative splicing of ASFMR1 seems to exhibit pre-mutation-specific profiles and is also silenced in FXS patients and upregulated in pre-mutation carriers, suggesting that a common process is responsible for regulating the expression of these transcripts. FMR4 is also silenced in FXS patients because of a CGG expansion repeat in the 5'UTR of the FMR1 gene and upregulated in pre-mutation carriers [77]; thus, their absence in the neurons of affected patients might contribute to the pathogenesis of this neurological disorder.

Another microsatellite expansion disease in which lncRNAs are involved is the spinocerebellar ataxia type 8 (SCA8), an autosomal dominant disorder, characterized by bidirectional transcription of this expansion repeat from opposite strands, forming both a protein-coding transcript encoding a polyglutamine expansion, ATXN8, and a lncRNA transcript containing a CUG expansion, ATXN8OS [78]. This suggests that SCA8 pathogenesis involves a toxic gain of function at both the protein and RNA levels. A recent study found that the expanded ATXN8OS transcript accumulates in ribonuclear inclusions in the GABAergic neurons of SCA8 patients [79]. These inclusions co-localized with splicing factor, MBNL1, altering the activity of MBNL alternative splicing proteins [79].

Huntington's disease (HD) is caused by an expansion repeat mutation in the Htt gene, which encodes a ubiquitously expressed 3144 amino acid protein of unknown function, leading to a toxic gain of function in the mutant protein [80], which promotes aberrant nuclear-cytoplasmic trafficking of the master neuronal regulator REST. The result is the deregulation of REST target gene expression in tissues from animal models of HD and human HD, which include both protein-coding genes as well as ncRNAs, such as lncRNAs. It is therefore likely that HD tissues are also characterized by dysregulation of lncRNA expression. ChiP-seq data showed that the HARl locus is under control of REST [81]. The HAR1 region contains lncRNAs, HARIF and HAR1R. HAR1F is specifically expressed in the neurons of the marginal zone during development of the cortex and in the frontal cortex, hippocampus, cerebellum, thalamus and hypothalamus in the adult brain [82]. The levels of HAR1F and HAR1R are decreased in HD brains compared with normal brains [83].

\subsubsection{LncRNAs in Neurodegenerative Diseases, such as Alzheimer's Disease (AD)}

$\beta$-site amyloid precursor protein-cleaving enzyme 1 (BACE1) is a crucial enzyme in AD pathophysiology, involved in the cleavage of the amyloid precursor protein $(A P P)$ and the generation of amyloid peptides which can aggregate and form plaques. Faghihi and colleagues characterized a conserved non-coding antisense transcript for BACE1, called BACE1-AS, which functions as a regulator of BACE1 gene expression. BACE1-AS upregulates BACE1 levels in response to a variety of stresses, including A $\beta$ 1-42 exposure, and is elevated in several brain regions of patients with AD. 
These findings imply that BACE1-AS is deregulated in $\mathrm{AD}$, which induces feed-forward regulation of BACE1, increases A $\beta$ levels, and thus may promote the pathogenesis of the disease [84].

Mus et al. found a link between altered levels of a lncRNA, BC200, and AD [85]. Increased levels of BC200 were found in brain regions that are preferentially affected in AD, such as the hippocampus, which correlated with disease severity. Further, in advanced stages of AD, BC200 was mis-localized and clustered in the perikaryon. These observations suggest that deregulation of this synaptic lncRNA is involved in the synaptic and neural network dysfunction that is found in both early and later stages of AD [85].

Together with neurological diseases, a number of psychiatric disorders have also been associated with lncRNAs (Table 1). The risk of developing schizophrenia (SZ), schizoaffective disorder, bipolar disorder, major depression, and autistic spectrum disorders has been linked to the disruption of the $D I S C$ genomic locus, which encodes both the DISC1 protein-coding gene and the DISC2 1ncRNA [86-88]. DISC2 controls the expression of its partner, DISC1, which modulates multiple aspects of CNS structure and function such as embryonic and adult neurogenesis [89]. Another lncRNA, Gomafu, implicated in brain and retinal development $[62,90]$ binds directly to the splicing factors QKI and SRSF1 and the dysregulation of Gomafu induces alternative splicing that resemble those observed in SZ for the archetypal SZ-associated genes DISC1 and ERB4. Moreover, Gomafu is downregulated in post-mortem cortex of SZ subjects, suggesting a role in SZ pathogenesis for this lncRNA [91].

Table 1. Examples of lncRNAs that are dysregulated in neurological disorders.

\begin{tabular}{|c|c|c|c|}
\hline IncRNA & Disease association & Biological function & Reference \\
\hline Ube3a-as & Angelman Syndrome & Repress paternal Ube $3 a$ expression & [72] \\
\hline ASFMR1 FMR4 & Fragile X Syndrome & $\begin{array}{l}\text { Regulate the expression of } A S F M R 1 \\
\text { and FMRI genes }\end{array}$ & {$[76,77]$} \\
\hline ATXN8OS & SCA8 & $\begin{array}{l}\text { Alteration of the activity of } \\
\text { the splicing factor } M B N L 1\end{array}$ & {$[78,79]$} \\
\hline HAR1F HAR1R & Hungtington's Disease & $\begin{array}{l}\text { Influence genes promoting aberrant } \\
\text { nuclear-cytoplasmatic trafficking } \\
\text { of } R E S T \text { gene }\end{array}$ & [83] \\
\hline BC200 BACE1-AS & Alzheimer's & $\begin{array}{l}\text { Involved in the synaptic and } \\
\text { neural network dysfunction } \\
\text { Regulates } B A C E 1 \text { gene expression }\end{array}$ & {$[84,85]$} \\
\hline DISC2 Gomafu & Psychiatric disorders & $\begin{array}{l}\text { Controls the expression of DISC1 } \\
\text { Implicated in brain } \\
\text { and retinal development }\end{array}$ & $\begin{array}{c}{[86-89]} \\
{[91]}\end{array}$ \\
\hline
\end{tabular}

\section{Conclusions and Future Perspectives}

Several recent studies suggest that lncRNAs play a pivotal role in many key biological processes, although their mechanisms of action are yet to be fully elucidated. Currently there is great interest in identifying the functions of this novel class of transcripts. There is strong evidence that many lncRNAs are biologically relevant, with a large percentage of these molecules functioning through their interactions with chromatin-modifying complexes to alter gene expression [3]. These findings are beginning to shed light on how chromatin-modifying complexes are targeted to specific genomic loci 
and suggest the interesting idea that lncRNAs are in some way driving chromatin-modifying complexes to genomic loci.

LncRNAs have, in a relatively short period of time, become recognized as a major new class of genes that may potentially comprise a major component of the genome's information content, complementary and comparable in abundance and complexity to the proteome. Furthermore lncRNAs have already been reported in a wide range of human diseases suggesting that their activity is crucial for human health.

In addition, therapeutic strategies that target endogenous mRNA molecules, such as those employing RNA interference (RNAi) and other customized oligonucleotide approaches with the capacity to reprogram disease-associated mRNAs, are now being developed [92]. These approaches could be adapted to target IncRNAs whose expression is dysregulated in CNS disorders. These observations suggest that lncRNAs represent a versatile class of factors that are centrally important to the modulation of different CNS processes and may represent a major layer underlying the genetic programming of brain development that could potentially be utilized for developing novel diagnostic and therapeutic tools for the cure of CNS disorders.

\section{Conflicts of Interest}

The authors declare no conflict of interest.

\section{References}

1. Mattick, J.S. Non-coding RNAs: The architects of eukaryotic complexity. EMBO 2001, 2, 986-991.

2. Harrow, J.; Frankish, A.; Gonzalez, J.M.; Tapanari, E.; Diekhans, M.; Kokocinski, F.; Aken, B.L.; Barrell, D.; Zadissa, A.; Searle, S.; et al. GENCODE: The reference human genome annotation for The ENCODE Project. Genome Res. 2012, 22, 1760-1774.

3. Khalil, A.M.; Guttman, M.; Huarte, M.; Garber, M.; Raj, A.; Rivea Morales, D.; Thomas, K.; Presser, A.; Bernstein, B.E.; van Oudenaarden, A.; et al. Many human large intergenic noncoding RNAs associate with chromatin-modifying complexes and affect gene expression. Proc. Natl. Acad. Sci. USA 2009, 106, 11667-11672.

4. Marques, A.C.; Ponting, C.P. Catalogues of mammalian long noncoding RNAs: Modest conservation and incompleteness. Genome Biol. 2009, 10, R124.

5. Guttman, M.; Amit, I.; Garber, M.; French, C.; Lin, M.F.; Feldser, D.; Huarte, M.; Zuk, O.; Carey, B.W.; Cassady, J.P.; et al. Lander Chromatin signature reveals over a thousand highly conserved large non-coding RNAs in mammals. Nature 2009, 458, 223-227.

6. Nagalakshmi, U.; Waern, K.; Snyder, M. RNA-Seq: A method for comprehensive transcriptome analysis. Curr. Protoc. Mol. Biol. 2010, doi:10.1002/0471142727.

7. Wang, E.T.; Sandberg, R.; Luo, S.; Khrebtukova, I.; Zhang, L.; Mayr, C.; Kingsmore, S.F.; Schroth, G.P.; Burge, C.B. Alternative isoform regulation in human tissue transcriptomes. Nature 2008, 456, 470-476.

8. Egger, G.; Liang, G.; Aparicio, A.; Jones, P.A. Epigenetics in human disease and prospects for epigenetic therapy. Nature 2004, 429, 457-463. 
9. Kaneda, M.; Okano, M.; Hata, K.; Sado, T.; Tsujimoto, N.; Li, E.; Sasaki, H. Essential role for de novo DNA methyltransferase Dnmt3a in paternal and maternal imprinting. Nature 2004, 429, 900-903.

10. Bernstein, B.E.; Meissner, A.; Lander, E.S. The mammalian epigenome. Cell 2007, 128, 669-681.

11. Gupta, R.A.; Shah, N.; Wang, K.C.; Kim, J.; Horlings, H.M.; Wong, D.J.; Tsai, M.C.; Hung, T.; Argani, P.; Rinn, J.L.; et al. Long non-coding RNA HOTAIR reprograms chromatin state to promote cancer metastasis. Nature 2010, 464, 1071-1076.

12. Reis, E.M.; Louro, R.; Nakaya, H.I.; Verjovski-Almeida, S. As antisense RNA gets intronic. OMICS 2005, 9, 2-12.

13. Tsai, M.C.; Manor, O.; Wan, Y.; Mosammaparast, N.; Wang, J.K.; Lan, F.; Shi, Y.; Segal, E.; Chang, H.Y. Long noncoding RNA as modular scaffold of histone modification complexes. Science 2010, 329, 689-693.

14. Mattick, J.S. The genetic signatures of noncoding RNAs. PLoS Genet. 2009, 5, e1000459.

15. Mattick, J.S.; Amaral, P.P.; Dinger, M.E.; Mercer, T.R.; Mehler, M.F. RNA regulation of epigenetic processes. Bioessays 2009, 31, 51-59.

16. Clark, M.B.; Mattick, J.S. Long noncoding RNAs in cell biology. Semin. Cell Dev. Biol. 2011, 22, 366-376.

17. Lyle, R.; Watanabe, D.; Vruchte, W.; Lerchner, O.; Smrzka, W. The imprinted antisense RNA at the Igf2r locus overlaps but does not imprint Mas1. Nat. Genet. 2000, 25, 19-21.

18. Schmidt, J.V.; Matteson, P.G.; Jones, B.K.; Guan, X.J.; Tilghman, S.M. The Dlk1 and Gtl2 genes are linked and reciprocally imprinted. Genes Dev. 2000, 14, 1997-2002.

19. Da Rocha, S.T.; Edwards, C.A.; Ito, M.; Ogata, T.; Ferguson-Smith, A.C. Genomic imprinting at the mammalian Dlk1-Dio3 domain. Trends Genet. 2008, 24, 306-316.

20. Williamson, C.M.; Turner, M.D.; Ball, S.T.; Nottingham, W.T.; Glenister, P. Identification of an imprinting control region affecting the expression of all transcripts in the Gnas cluster. Nat. Genet. 2006, 38, 350-355.

21. Nagano, T.; Mitchell, J.A.; Sanz, L.A.; Pauler, F.M.; Ferguson-Smith, A.C.; Feil, R.; Fraser, P. The Air noncoding RNA epigenetically silences transcription by targeting G9a to chromatin. Science 2008, 322, 1717-1720.

22. Zhao, J.; Sun, B.K.; Erwin, J.A.; Song, J.J.; Lee, J.T. Polycomb proteins targeted by a short repeat RNA to the mouse X chromosome. Science 2008, 322, 750-756.

23. Pandey, R.R.; Mondal, T.; Mohammad, F.; Enroth, S.; Redrup, L.; Komorowski, J.; Nagano, T.; Mancini-Dinardo, D.; Kanduri, C. Kcnq1ot1 antisense noncoding RNA mediates lineage-specific transcriptional silencing through chromatin-level regulation. Mol. Cell 2008, 32, 232-234.

24. Kanduri, C.; Thakur, N.; Pandey, R. The length of the transcript encoded from the Kcnq1ot1 antisense promoter determines the degree of silencing. EMBO J. 2006, 25, 2096-2106.

25. Bartolomei, M.S.; Zemel, S.; Tilghman, S.M. Parental imprinting of the mouse H19 gene. Nature 1991, 351, 153-155.

26. Brannan, C.I.; Dees, E.C.; Ingram, R.S.; Tilghman, S.M. The product of the H19 gene may function as an RNA. Mol. Cell Biol. 1990, 20, 28-36.

27. Gabory, A.; Jammes, H.; Dandolo, L. The H19 locus: Role of an imprinted non-coding RNA in growth and development. Bioessays 2010, 32, 473-480. 
28. Cai, X.; Cullen, B.R. The imprinted H19 noncoding RNA is a primary microRNA precursor. $R N A$ 2007, 13, 313-316.

29. Keniry, A.; Oxley, D.; Monnier, P.; Kyba, M.; Dandolo, L. The H19 lincRNA is a developmental reservoir of miR-675 that suppresses growth and Igf1r. Nat. Cell Biol. 2012, 14, 859-865.

30. Lee, J.T. Gracefully ageing at 50, X-chromosome inactivation becomes a paradigm for RNA and chromatin control. Nat. Rev. Mol. Cell Biol. 2011, 12, 815-826.

31. Brown, C.J.; Lafrenière, R.G.; Powers, V.E.; Sebastio, G.; Ballabio, A. Localization of the X inactivation centre on the human X chromosome in Xq13. Nature 1991, 349, 82-84.

32. Do, J.T.; Han, D.W.; Gentile, L.; Sobek-Klocke, I.; Stehling, M.; Schöler, H.R. Enhanced reprogramming of Xist by induced upregulation of Tsix and Dnmt3a. Stem Cells 2008, 26, 2821-2831.

33. Tian, D.; Sun, S.; Lee, J.T. The long noncoding RNA, Jpx, is a molecular switch for X chromosome inactivation. Cell 2010, 143, 390-403.

34. Pearson, J.C.; Lemons, D.; McGinnis, W. Modulating Hox gene functions during animal body patterning. Nat. Rev. Genet. 2005, 6, 893-904.

35. Rinn, J.L.; Kertesz, M.J.; Wang, K.; Squazzo, S.L.; Xu, X. Functional demarcation of active and silent chromatin domains in human HOX loci by noncoding RNAs. Cell 2007, 129, 1311-1323.

36. Bertani, S.; Sauer, S.; Bolotin, E.; Sauer, F. The noncoding RNA Mistral activates Hoxa6 and Hoxa7 expression and stem cell differentiation by recruiting MLL1 to chromatin. Mol. Cell 2011, 43, 1040-1046.

37. Wang, K.C.; Yang, Y.W.; Liu, B.; Sanyal, A.; Corces-Zimmerman, R. A long noncoding RNA maintains active chromatin to coordinate homeotic gene expression. Nature 2011b, 472, 120-124.

38. Bhan, A.; Hussain, I.; Ansari, K.I.; Kasiri, S.; Bashyal, A.; Mandal, S.S. Antisense Transcript Long Noncoding RNA (lncRNA) HOTAIR is transcriptionally induced by Estradiol. J. Mol. Biol. 2013, doi:10.1016/j.jmb.2013.01.022.

39. Guttman, M.; Donaghey, J.; Carey, B.W.; Garber, M.; Grenier, J.K.; Munson, G.; Young, G.; Lucas, A.B.; Ach, R.; Bruhn, L.; et al. lincRNAs act in the circuitry controlling pluripotency and differentiation. Nature 2011, 477, 295-300.

40. Loewer, S.; Cabili, M.N.; Guttman, M.; Loh, Y.H.; Thomas, K.; Park, I.H.; Garber, M.; Curran, M.; Onder, T.; Agarwal, S.; et al. Large intergenic non-coding RNA-RoR modulates reprogramming of human induced pluripotent stem cells. Nat. Genet. 2010, 42, 1113-1117.

41. Zhang, A.; Zhou, N.; Huang, J.; Liu, Q.; Fukuda, K.; Ma, D.; Lu, Z.; Bai, C.; Watabe, K.; Mo, Y.Y. The human long non-coding RNA-RoR is a p53 repressor in response to DNA damage. Cell Res. 2013, 23, 340-350.

42. Young, T.L.; Matsuda, T.; Cepko, C.L. The noncoding RNA taurine upregulated gene 1 is required for differentiation of the murine retina. Curr. Biol. 2005, 15, 501-512.

43. Feng, J.; Bi, C.; Clark, B.S.; Mady, R.; Shah, P.; Kohtz, J.D. The Evf-2 noncoding RNA is transcribed from the Dlx-5/6 ultraconserved region and functions as a Dlx-2 transcriptional coactivator. Genes Dev. 2006, 20, 1470-1484.

44. Bond, A.M.; Vangompel, M.J.; Sametsky, E.A.; Clark, M.F.; Savage, J.C.; Disterhoft, J.F. Balanced gene regulation by an embryonic brain ncRNA is critical for adult hippocampal GABA circuitry. Nat. Neurosci. 2009, 12, 1020-1027. 
45. Clemson, C.M.; Hutchinson, J.N.; Sara, S.A.; Ensminger, A.W.; Fox, A.H.; Chess, A.; Lawrence J.B. An architectural role for a nuclear noncoding RNA: NEAT1 RNA is essential for the structure of paraspeckles. Mol. Cell 2009, 33, 717-726.

46. Willingham, A.T.; Orth, A.P.; Batalov, S.; Peters, E.C.; Wen, B.G.; Aza-Blanc, P.; Hogenesch, J.B.; Schultz, P.G. A strategy for probing the function of noncoding RNAs finds a repressor of NFAT. Science 2005, 309, 1570-1573.

47. Gutschner, T.; Diederichs, S. The hallmarks of cancer: A long non-coding RNA point of view. RNA Biol. 2012, 9, 703-719.

48. Prensner, J.R.; Iyer, M.K.; Balbin, O.A.; Dhanasekaran, S.M.; Cao, Q. Transcriptome sequencing across a prostate cancer cohort identifies PCAT-1, an unannotated lincRNA implicated in disease progression. Nat. Biotechnol. 2011, 29, 742-749.

49. Kotake, Y.; Nakagawa, T.; Kitagawa, K.; Suzuki, S.; Liu, N. Long non-coding RNA ANRIL is required for the PRC2 recruitment to and silencing of p15(INK4B) tumor suppressor gene. Oncogene 2011, 30, 1956-1962.

50. Yang, Z.; Zhou, L.; Wu, L.M.; Lai, M.C.; Xie, H.Y.; Zhang, F.; Zheng, S.S. Overexpression of long non-coding RNA HOTAIR predicts tumor recurrence in hepatocellular carcinoma patients following liver transplantation. Ann. Surg. Oncol. 2011, 18, 1243-1250.

51. Kogo, R.; Shimamura, T.; Mimori, K.; Kawahara, K.; Imoto, S.; Sudo, T.; Tanaka, F.; Shibata, K.; Suzuki, A.; Komune, S.; et al. Long noncoding RNA HOTAIR regulates polycombdependent chromatin modification and is associated with poor prognosis in colorectal cancers. Cancer Res. 2011, 71, 6320-6326.

52. Niinuma, T.; Suzuki, H.; Nojima, M.; Nosho, K.; Yamamoto, H. Upregulation of miR-196a and HOTAIR drive malignant character in gastrointestinal stromal tumors. Cancer Res. 2012, 72, $1126-1136$.

53. Kim, K.; Jutooru, I.; Chadalapaka, G.; Johnson, G.; Frank J.; Burghardt, R.; Kim, S.; Safe, S. HOTAIR is a negative prognostic factor and exhibits pro-oncogenic activity in pancreatic cancer. Oncogene 2012, doi:10.1038/onc.2012.193.

54. Lin, R.; Roychowdhury-Saha, M.; Black, C.; Watt, A.T.; Marcusson, E.G. Control of RNA processing by a large non-coding RNA over-expressed in carcinomas. FEBS Lett. 2011, 585, 671-676.

55. Tano, K.; Mizuno, R.; Okada, T.; Rakwal, R.; Shibato, J. MALAT-1 enhances cell motility of lung adenocarcinoma cells by influencing the expression of motility-related genes. FEBS Lett. 2010, 584, 4575-4580.

56. Ishii, N.; Ozaki, K.; Sato, H.; Mizuno, H.; Saito, S.; Takahashi, A.; Miyamoto, Y.; Ikegawa, S.; Kamatani, N.; Hori, M.; et al. Identification of a novel non-coding RNA, MIAT, that confers risk of myocardial infarction. J. Hum. Genet. 2006, 51, 1087-1099.

57. Broadbent, H.M.; Peden, J.F.; Lorkowski, S.; Goel, A.; Ongen, H.; Green, F.; Clarke, R.; Collins, R.; Franzosi, M.G.; Tognoni, G.; et al. PROCARDIS consortium. Susceptibility to coronary artery disease and diabetes is encoded by distinct, tightly linked SNPs in the ANRIL locus on chromosome 9p. Hum. Mol. Genet. 2008, 17, 806-814. 
58. Cabianca, D.S.; Casa, V.; Bodega, B.; Xynos, A.; Ginelli, E.; Tanaka, Y.; Gabellini, D. Long ncRNA links copy number variation to a polycomb/trithorax epigenetic switch in FSHD muscular dystrophy. Cell 2012, 149, 819-831.

59. Van Dijk, M.; Thulluru, H.K.; Mulders, J.; Michel, O.J.; Poutsma, A. Windhorst, HELLP babies link a novel lincRNA to the trophoblast cell cycle. J. Clin. Invest. 2012, 122, 4003-4011.

60. Mercer, T.R.; Dinger, M.E.; Sunkin, S.M.; Mehler, M.F.; Mattick, J.S. Specific expression of long noncoding RNAs in the mouse brain. Proc. Natl. Acad. Sci. USA 2008, 105, 716-721.

61. Ponjavic, J.; Oliver, P.L.; Lunter, G.; Ponting, C.P. Genomic and transcriptional co-localization of protein-coding and long non-coding RNA pairs in the developing brain. PLoS Genet. 2009, 5, e1000617.

62. Mercer, T.R.; Qureshi, I.A.; Gokhan, S.; Dinger, M.E.; Li, G.; Mattick, J.S.; Mehler, M.F. Long noncoding RNAs in neuronal-glial fate specification and oligodendrocyte lineage maturation BMC Neurosci. 2010, 11, 14.

63. Fantes, J.; Ragge, N.K.; Lynch, S.A.; McGill, N.I.; Collin, J.R.; Howard-Peebles, P.N.; Hayward, C.; Vivian, A.J.; Williamson, K.; van Heyningen V.; et al. Mutations in SOX2 cause anophthalmia. Nat. Genet. 2003, 33, 461-463.

64. Amaral, P.P.; Neyt, C.; Wilkins, S.J.; Askarian-Amiri, M.E.; Sunkin, S.M.; Perkins, A.C.; Mattick, J.S. Complex architecture and regulated expression of the Sox2ot locus during vertebrate development. RNA 2009, 15, 2013-2027.

65. Tochitani, S.; Hayashizaki, Y. Nkx2.2 antisense RNA overexpression enhanced oligodendrocytic differentiation. Biochem. Biophys. Res. Commun. 2008, 372, 691-696.

66. Brosius, J. RNAs from all categories generate retrosequences that may be exapted as novel genes or regulatory elements. Gene 1999, 238, 115-134.

67. Kondrashov, A.V.; Kiefmann, M.; Ebnet, K.; Khanam, T.; Muddashetty, R.S.; Brosius, J. Inhibitory effect of naked neural $\mathrm{BC} 1 \mathrm{RNA}$ or $\mathrm{BC} 200 \mathrm{RNA}$ on eukaryotic in vitro translation systems is reversed by poly(A)-binding protein (PABP). J. Mol. Biol. 2005, 353, 88-103.

68. Lin, D.; Pestova, T.V.; Hellen, C.U.; Tiedge, H. Translational control by a small RNA: Dendritic BC1 RNA targets the eukaryotic initiation factor 4A helicase mechanism. Mol. Cell. Biol. 2008, $28,3008-3019$.

69. Martignetti, J.A.; Brosius, J. BC200 RNA: A neural RNA polymerase III product encoded by a monomeric Alu element. Proc. Natl. Acad. Sci. USA 1993, 90, 11563-11567.

70. French, P.J.; Bliss, T.V.; O'Connor, V. Ntab, a novel non-coding RNA abundantly expressed in rat brain. Neuroscience 2001, 108, 207-215.

71. Bernard, D.; Prasanth, K.V.; Tripathi, V.; Colasse, S.; Nakamura, T.; Xuan, Z.; Zhang, M.Q.; Sedel, F.; Jourdren, L.; Coulpier. F.; et al. A long nuclear-retained non-coding RNA regulates synaptogenesis by modulating gene expression. EMBO J. 2010, 29, 3082-3093.

72. Williams, C.J. Angelman syndrome scientific symposium on the structure and function of UBE3A/E6AP. Child Neurol. 2009, 24, 904-908.

73. Chamberlain, S.J.; Brannan, C.I. The Prader-Willi syndrome imprinting center activates the paternally expressed murine Ube3a antisense transcript but represses paternal Ube3a. Genomics 2001, 73, 316-322. 
74. Johnstone, K.A.; DuBose, A.J.; Futtner, C.R.; Elmore, M.D.; Brannan, C.I.; Resnick, J.L. A human imprinting centre demonstrates conserved acquisition but diverged maintenance of imprinting in a mouse model for Angelman syndrome imprinting defects. Hum. Mol. Genet. 2006, $15,393-404$.

75. Yamasaki, K.; Joh, K.; Ohta, T.; Masuzaki, H.; Ishimaru, T.; Mukai, T.; Niikawa, N.; Ogawa, M.; Wagstaff, J.; Kishino, T. Neurons but not glial cells show reciprocal imprinting of sense and antisense transcripts of Ube3a. Hum. Mol. Genet. 2003, 15, 837-847.

76. Khalil, A.M.; Faghihi, M.A.; Modarresi, F.; Brothers, S.P.; Wahlestedt, C. A novel RNA transcript with antiapoptotic function is silenced in fragile $\mathrm{X}$ syndrome. PLoS One 2008, 3, e1486.

77. Ladd, P.D.; Smith, L.E.; Rabaia, N.A.; Moore, J.M.; Georges, S.A.; Hansen, R.S.; Hagerman, R.J.; Tassone, F.; Tapscott, S.J.; Filippova, G.N. An antisense transcript spanning the CGG repeat region of FMR1 is upregulated in premutation carriers but silenced in full mutation individuals. Hum. Mol. Genet. 2007, 16, 3174-3187.

78. Moseley, M.L.; Zu, T.; Ikeda, Y.; Gao, W.; Mosemiller, A.K.; Daughters, R.S.; Chen, G.; Weatherspoon, M.R.; Clark, H.B.; et al. Ranum Bidirectional expression of CUG and CAG expansion transcripts and intranuclear polyglutamine inclusions in spinocerebellar ataxia type 8 . Nat. Genet. 2006, 38, 758-769.

79. Daughters, R.S.; Tuttle, D.L.; Gao, W.; Ikeda, Y.; Moseley, M.L.; Ebner, T.J.; Swanson, M.S.; Ranum, L.P. RNA gain-of-function in spinocerebellar ataxia type 8. PLoS Genet. 2009, 5, e1000600.

80. Scahill, R.I.; Wild, E.J.; Tabrizi, S.J. Biomarkers for Huntington's disease: An update. Expert Opin. Med. Diagn. 2012, 6, 371-375.

81. Johnson, D.S.; Mortazavi, A.; Myers, R.M.; Wold, B. Genome-Wide mapping of in vivo protein-DNA interactions. Science 2007, 316, 1497-1502.

82. Pollard, K.S.; Salama, S.R.; Lambert, N.; Lambot, M.A.; Coppens, S.; Pedersen, J.S.; Katzman, S.; King, B.; Onodera, C.; et al. An RNA gene expressed during cortical development evolved rapidly in humans. Nature 2006, 443, 167-172.

83. Johnson, R.; Richter, N.; Jauch, R.; Gaughwin, P.M.; Zuccato, C.; Cattaneo, E.; Stanton, L.W. The human accelerated region 1 noncoding RNA is repressed by REST in Huntington's disease. Physiol. Genomics 2010, 41, 269.

84. Faghihi, M.A.; Modarresi, F.; Khalil, A.M.; Wood, D.E.; Sahagan, B.G.; Morgan, T.E.; Finch, C.E.; St Laurent, G.; Kenny, P.J.; Wahlestedt, C. Expression of a noncoding RNA is elevated in Alzheimer's disease and drives rapid feed-forward regulation of beta-secretase. Nat. Med. 2008, 14, 723-730.

85. Mus, E.; Hof, P.R.; Tiedge, H. Dendritic BC200 RNA in aging and in Alzheimer's disease. Proc. Natl. Acad. Sci. USA 2007, 104, 10679-10684.

86. Chubb, J.E.; Bradshaw, N.J.; Soares, D.C.; Porteous, D.J.; Millar, J.K. The DISC locus in psychiatric illness. Mol. Psychiatr. 2008, 13, 36-64.

87. Millar, J.K.; Wilson-Annan, J.C.; Anderson, S.; Christie, S.; Taylor, M.S.; Semple, C.A.; Devon, R.S.; St Clair, D.M.; Muir, W.J.; Blackwood, D.H.; et al. Disruption of two novel genes by a translocation co-segregating with schizophrenia. Hum. Mol. Genet. 2000, 9, 1415-1423. 
88. Williams, J.M.; Beck, T.F.; Pearson, D.M.; Proud, M.B.; Cheung, S.W.; Scott, D.A. A 1q42 deletion involving DISC1, DISC2, and TSNAX in an autism spectrum disorder. Am. $J$. Med. Genet. 2009, 149A, 1758-1762.

89. Brandon, N.J.; Millar, J.K.; Korth, C.; Sive, H.; Singh, K.K.; Sawa, A. Understanding the role of DISC1 in psychiatric disease and during normal development. J. Neurosci. 2009, 29, 12768-12775.

90. Rapicavoli, N.A.; Blackshaw, S. New meaning in the message: Noncoding RNAs and their role in retinal development. Dev. Dyn. 2009, 238, 2103-2114.

91. Barry, G.; Briggs, J.A.; Vanichkina, D.P.; Poth, E.M.; Beveridge, N.J.; Ratnu, V.S.; Nayler, S.P.; Nones, K.; Hu, J.; Bredy, T.W.; et al. The long non-coding RNA Gomafu is acutely regulated in response to neuronal activation and involved in schizophrenia-associated alternative splicing. Mol. Psychiatr. 2013, doi:10.1038/mp.2013.45.

92. Wood, M.; Yin, H.; McClorey, G. Modulating the expression of disease genes with RNA-based therapy. PLoS Genet. 2007, 3, e109.

(C) 2013 by the authors; licensee MDPI, Basel, Switzerland. This article is an open access article distributed under the terms and conditions of the Creative Commons Attribution license (http://creativecommons.org/licenses/by/3.0/). 